\title{
O papel das universidades e os núcleos de prática jurídica: o caso do Centro de Assistência Jurídica da Universidade Federal Fluminense Campus Macaé
}

\author{
Ully Hashimoto Mayerhofer 1 \\ Universidade Federal Fluminense
}

\begin{abstract}
RESUMO
As universidades possuem um importante papel na sociedade e têm como pilares o ensino, pesquisa e extensão. No município de Macaé, observa-se que as universidades públicas e privadas ali instaladas são bastante atuantes, com a oferta de diversas atividades e serviços à população, nas mais variadas áreas do conhecimento, especialmente aquelas relacionadas aos cursos por elas oferecidos nessas unidades. Assim, o presente trabalho pretende dedicar-se ao estudo das diversas iniciativas das universidades que impactam diretamente a população, dentre elas se encontram os núcleos de prática jurídica, tais como o CAJUFF Macaé. Para tanto, buscou-se apresentar um breve relato sobre a evolução do CAJUFF Macaé, com a apresentação de dados acerca dos atendimentos e exposição das demais atividades desenvolvidas no escritório modelo, ressaltando seu desenvolvimento ao longo dos anos. O núcleo de prática do ICM/UFF Macaé vai além de uma exigência acadêmica formal, pois contribui para uma formação de qualidade para os alunos da graduação do curso de Direito e oferece assistência jurídica gratuita à sociedade. A pesquisa baseou-se no contato com as instituições analisadas por meio de seus portais oficiais e dos atores envolvidos nas atividades, bem como em diplomas legais e revisão bibliográfica. Este trabalho objetiva contribuir para a valorização e visibilidade dos trabalhos realizados pelas instituições de ensino superior localizadas no município através da análise mais aprofundada do CAJUFF Macaé, bem como ressaltar a necessidade de investimento, de forma a permitir a continuidade e qualidade dos serviços ofertados.
\end{abstract}

Palavras-chave: Universidades. Núcleos de prática jurídica. Sociedade. CAJUFF Macaé.

\begin{abstract}
Universities play an important role in society and have as pillars the teaching, research and extension. In the city of Macaé, it is observed that the public and private universities installed there are quite active, offering various activities and services to the population, in the most varied areas of knowledge, especially those related to the courses offered by them in these units. Thus, the present work intends to dedicate itself to the study of the diverse initiatives of the universities that directly impact the population, among them are the nuclei of legal practice, such as CAJUFF Macaé. To this end, we sought to present a brief report on the evolution of CAJUFF Macaé, with the presentation of data about the services and exposure of other activities developed in the model office, highlighting its development over the years. The ICM/UFF Macaé practice nucleus goes beyond a formal academic requirement, since it contributes to quality training for undergraduate students of the Law course and offers free legal assistance to society. The research was based on contact with the institutions analyzed through their official portals and the actors involved in the activities, as well as on legal diplomas and bibliographic review. This work aims to contribute to the valorization and visibility of the works carried out by higher education institutions located in the city through the more in-depth analysis of CAJUFF Macaé, as well as to emphasize the need for investment, in order to allow the continuity and quality of the services offered.
\end{abstract}

Keywords: Universities. Legal practice nuclei. Society. CAJUFF Macaé. 


\section{Introdução}

As instituições de ensino superior têm um papel muito importante na sociedade, baseado nos pilares ensino, pesquisa e extensão. Esse tripé está previsto, inclusive, no artigo 207 da Constituição Federal (1988), que determina sua indissociabilidade.

As universidades impactam a sociedade, seja movimentando a economia da região na qual estão inseridas ou promovendo a disseminação do conhecimento. Essas instituições são capazes de colaborar com o desenvolvimento político e social da população através de suas atividades, que vão muito além do conhecimento acadêmico apenas aos seus alunos, mas por meio dos mais variados serviços por elas ofertados.

As instituições de ensino superior proporcionam diversas atividades que envolvem a população através de projetos de pesquisa, projetos de extensão e estágio supervisionado, em órgãos públicos ou mesmo nas dependências da própria universidade, gratuitos em sua grande maioria.

No município de Macaé, atualmente estão situadas universidades públicas Universidade Federal Fluminense (UFF), Universidade Federal do Rio de Janeiro (UFRJ), Faculdade Miguel Ângelo da Silva Santos (FeMASS) e Instituto Federal Fluminense (IFF) - e privadas - Universidade de Ensino Superior Estácio de Sá, Faculdade Salesiana Maria Auxiliadora (FSMA), Faculdade de Filosofia, Ciências e Letras de Macaé (FAFIMA) e Universidade Unigranrio - que oferecem diversos cursos, das mais variadas áreas.

$\mathrm{O}$ atendimento jurídico gratuito é um exemplo de iniciativa das universidades, que buscam oferecer relevantes serviços gratuitamente à comunidade em que estão situadas, tais como atendimento psicológico, auxílio para elaboração do imposto de renda e atividades envolvendo projetos de extensão em diversos seguimentos.

O objetivo deste artigo é estudar um caso específico de práticas jurídicas oferecidas por um dos escritórios modelos, o Centro de Assistência Jurídica da Universidade Federal Fluminense Campus Macaé (CAJUFF Macaé) para inferir o papel desempenhado na contribuição à sociedade.

A metodologia utilizada é um estudo de caso. Para a elaboração deste estudo, foram utilizados como base de pesquisa, de forma a servir como inspiração para a escrita e aprofundamento do tema, artigos e trabalhos monográficos que abordam certos aspectos envolvendo a temática em questão, bem como diplomas legais acerca das diretrizes curriculares nacionais do curso de graduação em Direito e a própria Constituição Federal.

Ademais, foram realizadas consultas às diversas instituições aqui citadas, pessoalmente, por contato telefônico e através dos atores envolvidos nas atividades, sendo alunos, residentes, professores ou funcionários que atuam ou já atuaram nesses locais.

Os dados referentes ao CAJUFF Macaé foram fornecidos por residentes e professores atuantes no núcleo de prática, com base nos registros feitos em relatórios de atendimentos e acompanhamentos processuais por eles elaborados ao longo das atividades.

Foram localizadas ainda matérias e notícias nos portais oficiais das instituições de ensino aqui citadas e da Prefeitura Municipal de Macaé, com relevantes dados sobre as iniciativas desenvolvidas no município e região.

O tema objeto do presente estudo mostra-se atual e relevante. A partir da observação e análise do desenvolvimento das diversas iniciativas das universidades situadas no município de Macaé, especialmente os núcleos de prática jurídica como o CAJUFF Macaé.Foi possível identificar, ao longo do tempo, diversos avanços, mas ainda há muitos pontos que demandam investimento e atenção.

A escolha da temática busca ainda contribuir para a valorização dos trabalhos realizados pelas instituições de ensino superior localizadas no município através da análise mais aprofundada do CAJUFF Macaé, bem como chamar a atenção para as necessidades estruturais necessárias ao desenvolvimento de um bom trabalho, tais como espaço físico, equipamentos, corpo docente, residentes e técnico-administrativos.

Para tanto, o presente artigo está organizado em quatro (04) seções. Inicialmente 
buscou-se apresentar as diversas iniciativas desenvolvidas pelas instituições de ensino superior de Macaé, descrevendo suas principais atividades voltadas à sociedade.

Em seguida, tratou-se dos núcleos de prática propriamente ditos, apresentando sua previsão e regulamentação, bem como sua importância e obrigatoriedade. Nesse tópico, ainda foi realizada uma breve revisão bibliográfica relevante à melhor compreensão do tema, abordando alguns dos relevantes estudos localizados sobre o assunto.

Finalmente, optou-se por dedicar uma seção específica para a análise do CAJUFF Macaé, de modo a apresentar suas principais características, o histórico de sua criação, seus objetivos e parcerias, perpassando por um relato sobre os editais de residência jurídica. Além disso, um tópico voltou-se à exposição do tipo de demandas recebidas e dos dados mais recentes relativos aos atendimentos, divididos por área. Ao final, foram pontuadas considerações sobre a importância e contribuição do CAJUFF Macaé para a sociedade, além de impressões sobre as perspectivas futuras sobre o núcleo de prática.

\section{Iniciativas das Universidades Situadas no Município de Macaé}

As universidades, de uma forma geral, desenvolvem atividades envolvendo a população dos municípios e entorno voltadas para os domínios cognitivos dos cursos que oferecem, normalmente vinculadas ao estágio curricular obrigatório, projetos de pesquisa e projetos de extensão. Essas formas de atuação das universidades procuram retribuir à comunidade parte do conhecimento difundido nas salas de aula, além de complementar qualitativamente com práticas para a formação dos seus alunos.

Em Macaé, as instituições de ensino superior são muito atuantes e promovem diversas atividades envolvendo a comunidade em geral, com a oferta de serviços das mais variadas áreas do conhecimento.

Dentre as instituições privadas que possuem iniciativas para a sociedade na região, é possível citar a Universidade Estácio de Sá e a FSMA. A unidade da Estácio de Sá em Macaé dispõe de uma clínica de psicologia, onde são realizados atendimentos à população, havendo ainda parceria com a Prefeitura Municipal de Macaé para atendimento às escolas da Rede (alunos, professores e servidores da Educação).

Ademais, ofertam o curso de Direito, motivo pelo qual possuem um núcleo de prática jurídica situado na sede da instituição, atuante nas áreas cível, previdenciário, família e trabalhista. O atendimento é totalmente gratuito e a seleção dos assistidos considera seu perfil socioeconômico. Além disso, o núcleo de primeiro atendimento do Juizado Especial Cível da Comarca de Macaé presente no Fórum Estadual da cidade funciona com alunos e funcionários da Estácio de Sá, também de forma gratuita.

A Faculdade Salesiana dispõe da Clínica Escola de Psicologia Santa Teresa, que oferece atendimento psicológico e o serviço de orientação vocacional/profissional. Seu público-alvo abrange crianças, adolescentes, adultos, idosos e grupos, os quais devem passar por uma entrevista de triagem.

No que se refere às instituições públicas, é possível citar a UFRJ e a UFF, pois promovem atividades voltadas à população. A UFRJ dispõe de projetos de extensão do curso de nutrição voltados às áreas de alimentação complementar e aleitamento materno, que se desenvolvem em diversos órgãos, notadamente os municipais, tais como o Hospital Público Municipal (HPM), as unidades da Estratégia de Saúde da Família (ESF) e os Centros de Referência de Assistência Social (CRAS). Há ainda atividades de estágio curricular obrigatório realizadas no Centro de Referência do Adolescente (CRA).

O Instituto de Biodiversidade e Sustentabilidade (NUPEM/UFRJ) desenvolve projetos de extensão como o vinculado ao curso de graduação em ciências biológicas que promoveu uma capacitação para elaboração de adubo orgânico. A atividade envolveu alunos da graduação, alunos do mestrado profissional, docentes e técnicos do NUPEM/UFRJ, além de membros da localidade do Barreto (Universidade Federal do Rio de Janeiro [UFRJ], 2020b).

O Instituto realizou ainda recentemente a primeira edição do evento "NUPEM/UFRJ com Ciência para Crianças", onde crianças tiveram acesso às coleções biológicas da instituição 
e conheceram mais sobre biodiversidade, aproveitando o período das férias escolares para aproximar as crianças à ciência e às pesquisas (UFRJ, 2020a).

A UFF, por meio do curso de ciências contábeis, oferece o chamado Sabadão do Leão, onde ocorre orientação e auxílio aos contribuintes para a transmissão da declaração do imposto de renda. Os atendimentos são gratuitos e são realizados pelos alunos da graduação, com a supervisão de professores.

Há ainda o núcleo de prática jurídica, o CAJUFF Macaé, situado no Pólo Universitário, vinculado ao Departamento de Direito do Instituto de Ciências da Sociedade de Macaé (ICM) da UFF, que oferece à população atendimento jurídico gratuito nas áreas cível, trabalhista e família/sucessões. O núcleo atua com alunos, professores, residentes e técnico-administrativos, e será abordado mais detalhadamente adiante.

O ICM dispõe de diversos projetos de inserção social, tais como o Núcleo de Apoio Contábil e Fiscal (NAF), o Laboratório de Pesquisa, Ensino e Extensão Gestão de Pessoas, Subjetividade, Organizações e Trabalho (LAPEEX PSOT) e o Núcleo de Estudos Afro-brasileiro e Indígena da Cidade Universitária de Macaé (NEABI). Há ainda as empresas juniores Destra Assessoria Jurídica Júnior, Merx Assessoria Júnior e Constatar Consultoria Júnior.

Além disso, a UFF desenvolve projetos de pesquisa e extensão vinculados aos seus mais variados cursos, dentre eles o Café com RH, Cidadania Ativa e Maria da Penha nas Escolas.

\section{Núcleos de Prática Jurídica}

Os alunos da graduação do curso de Direito, assim como em outros cursos, possuem, em sua grade curricular, o estágio como elemento obrigatório para sua conclusão. A experiência prática vai além de uma exigência formal, ele complementa ricamente a formação do estudante, permitindo a vivência profissional antes mesmo do recebimento do diploma. A previsão e a regulamentação dos núcleos de prática das Faculdades de Direito encontra-se na Portaria $n^{\circ} 1.886$ (1994) do Ministério da Educação (MEC) detalhada em seus artigos 10 e 11. O referido Diploma trouxe como uma das principais inovações para as diretrizes curriculares do curso de Direito o eixo de formação prática, a ser desenvolvido através das atividades concretas e simuladas no núcleo de prática jurídica, com a devida supervisão pedagógica.

Nesse sentido, a Resolução CNE/CES n 9 (2004) do Ministério da Educação, que trata das diretrizes curriculares nacionais do curso de graduação em Direito, determina, em seu artigo $7^{\circ}, \S 1^{\circ}$, que o estágio pode contemplar convênios com outras entidades ou instituições e escritórios de advocacia; serviços de assistência judiciária implantados na própria instituição, nos órgãos do Poder Judiciário, Ministério Público, Defensoria Pública, ou mesmo em departamentos jurídicos oficiais. Em todas as hipóteses, deverá haver supervisão das atividades e elaboração de relatórios a serem apresentados à coordenação de estágio da Instituição de Ensino, para avaliação.

Os núcleos de prática, ou escritórios modelos, são os locais situados nas universidades para o desenvolvimento das atividades práticas por meio do atendimento ao público com consultoria jurídica, elaboração de peças processuais, estudo de casos reais e simulados, análise jurisprudencial, realização de visitas institucionais, acompanhamento de audiências, além da troca de experiências entre alunos, professores e residentes.

Assim como as Defensorias Públicas, os núcleos de prática jurídica são importantes meio de acesso à justiça a pessoas que não possuem meios de arcar financeiramente com os custos de um processo judicial, especialmente no que se refere a honorários advocatícios. Nesse sentido, os centros de assistência jurídica auxiliam os necessitados a ingressar com suas demandas no Poder Judiciário ou mesmo a obter consultoria jurídica de forma gratuita.

Ademais, os escritórios modelos são para além de formalmente obrigatórios, mas essenciais para uma formação de qualidade para os alunos da graduação do curso de Direito, sendo a ocasião propícia para um contato direto com a atuação prática profissional, sob a supervisão e orientação do professor, bem como a contribuição do residente jurídico.

O município de Macaé dispõe, atualmente, de duas instituições de ensino superior com a oferta do curso de Direito, sendo uma pública, a Universidade Federal Fluminense, e outra 
privada, a Universidade Estácio de Sá. Ambas as instituições possuem núcleos de prática jurídica fortemente atuantes.

\section{Revisão Bibliográfica}

A literatura pesquisada sobre os núcleos de prática jurídica trata principalmente de sua função pedagógica aos alunos da graduação mas também como recurso de universalização do acesso à justiça no que se refere à assistência jurídica integral e gratuita à população hipossuficiente.

Hudler e Furtado (2015) reconhecem a função social dos núcleos de prática e consideram que a participação direta dos alunos nos casos concretos e simulados contribui para sua formação, permitindo uma reflexão crítica, bem como o contato com a realidade e a atuação prática.

Cabe ressaltar que os atendimentos jurídicos nos escritórios modelos são obrigatoriedades vinculadas ao curso de Direito, não se tratando de atividades de extensão propriamente ditas. No entanto, não se pode ignorar suas semelhanças, principalmente no que se refere aos seus objetivos comuns.

Ambas as atividades assemelham-se no que diz respeito à busca pela formação profissional e humanística, permitindo a inserção do acadêmico na realidade cotidiana. Nesse sentido, Deslandes e Arantes (2017) entendem que "o meio está inserido na formação curricular acadêmica, assim como a academia deve estar inserida no meio em que se encontra".

Cumpre ressaltar que a prática objetiva o aperfeiçoamento do aprendizado acadêmico, contribuindo na obtenção de autoconfiança, conhecimento profissional, melhoria do currículo e aumento das possibilidades de ingresso no mercado de trabalho (Deslandes \& Arantes, 2017).

Quanto ao CAJUFF Macaé, foram localizados trabalhos abordando prioritariamente os meios alternativos de resolução de conflitos, com foco na mediação, em que os autores analisam os benefícios do emprego das práticas consensuais aos conflitos sociais (Santos \& Ferreira, 2012; Santos, Pimentel, \& Marques, 2015; Santos \& Rezende, 2013; Santos, Yagodnik, \& Marques, 2014).

Insta salientar que os núcleos de prática correspondem, inclusive, a um dos critérios avaliados pelo MEC e pela Ordem dos Advogados do Brasil (OAB) como indicador de conceituação do curso, considerando suas condições de instalação, recursos materiais e humanos próprios e adequados, o que enfatiza sua importância (Bello \& Ferreira, 2018; Sousa, 2006).

Assim, é possível observar a identificação de trabalhos abordando a temática da prática jurídica, especialmente quanto aos núcleos de prática. No entanto, considera-se necessária a contínua produção de material relevante e atual sobre essa importante iniciativa das universidades, bem como trazer novos assuntos para o foco do debate.

\section{Estudo de Caso CAJUFF Macaé}

A UFF atualmente oferece no município de Macaé os cursos de bacharelado em Administração, Ciências Contábeis e Direito. A instalação dos dois primeiros cursos ocorreu em 1992 e começou a funcionar em março de 1993, através de um convênio com a Prefeitura Municipal de Macaé, por meio da Fundação Educacional de Macaé (FUNEMAC), funcionando inicialmente como uma extensão dos cursos de Niterói. (Universidade Federal Fluminense [UFF], 2019)

O curso da graduação em Direito foi instalado em 2001, por meio de um convênio entre a universidade e o Governo do Estado do Rio de Janeiro. Até o ano de 2005 funcionava como uma extensão da Faculdade de Direito de Niterói. (UFF, 2019)

Em 2011, houve a criação dos Departamentos de Direito e de Administração e Contabilidade, este último posteriormente dividido em duas partes. Em 2012, foi instituído o campus da universidade em Macaé. Finalmente, em 2013, foi criada a unidade independente 
e passou a ser intitulada ICM, resultando em uma maior autonomia dos cursos, com currículo e grade próprios. (UFF, 2019)

O CAJUFF Macaé está vinculado ao Departamento de Direito do ICM/UFF Macaé e, a partir de 21 de março de 2018, passou a ser intitulado Núcleo de Prática Jurídica Professora Carla Fernandes de Oliveira, em homenagem à professora que integrou o corpo docente da instituição (UFF, 2018).

O núcleo de prática, criado em 2006, possui regulamento próprio que disciplina suas atividades, definindo sua administração e requisitos, detalhando a carga horária dos estagiários e demais regramentos acerca do estágio obrigatório.

$\mathrm{Na}$ UFF, o núcleo de atendimento jurídico vincula-se ao estágio supervisionado, em que os alunos, acompanhados dos professores e dos residentes, têm a oportunidade de vivenciar a atuação prática através de atendimentos a casos reais, desenvolvimento da escuta, discussão dos casos concretos e possibilidades de resolução, orientação sobre a postura profissional, elaboração de peças processuais, visitas a órgãos públicos, acompanhamento processual, análise e aplicação de jurisprudência, dentre outros.

Acredita-se na importância da complementação mútua entre teoria e prática para um ensino de qualidade, que oportuniza aos alunos a prática de sua futura profissão, bem como o contato com outros profissionais atuantes na área, integrando os aspectos teóricos aos práticos, o que representa o principal objetivo dos estágios supervisionados.

Considerando tal relevância, o estudo dos núcleos de prática, em especial do CAJUFF Macaé, busca contribuir para a demonstração de sua importância para a comunidade onde estão inseridos, visando conceder a devida atenção ao trabalho neles desenvolvidos e ampliar a qualidade e a abrangência dos atendimentos.

\section{Objetivos e Parcerias do CAJUFF}

O principal objetivo do CAJUFF é oferecer estágio curricular aos alunos cursando do $7^{\circ}$ ao $9^{\circ}$ períodos de Direito no ICM, além de ofertar assistência jurídica consultiva à população hipossuficiente, considerando o aspecto socioeconômico.

Ademais, o núcleo possui ainda parcerias com outras instituições, dentre elas o Centro Especializado de Atendimento à Mulher de Macaé (CEAM), o Centro de Referência em Inovação para Operações Sustentáveis (CRIOS UFRJ) e a Associação de Engenheiros Sem Fronteiras - UFF Rio das Ostras (ESF-RDO), de modo a prestar apoio acadêmico e consultivo.

Em 2008, foi lançado um edital de residência jurídica na UFF, sendo ofertadas duas (02) vagas para Macaé, em parceria com a Prefeitura Municipal de Macaé, com início das atividades no primeiro semestre de 2009. A residência previu a duração de dois anos e carga horária de 40 horas semanais. A seleção dos candidatos foi composta por uma prova escrita e análise de currículo. Na ocasião, houve oferta de bolsa para ajuda de custo, exigindo dedicação exclusiva.

Foram desenvolvidos na UFF Macaé os projetos de extensão "Meios alternativos de solução de conflitos no Centro de Assistência Judiciária - CAJUFF/Macaé" (Santos, Yagodnik, \& Marques, 2014) e "Mediação na Assistência Jurídica: conscientizando-se a população sobre esta alternativa", envolvendo os advogados residentes e alunos estagiários do CAJUFF Macaé. Com isso, buscou-se "colocar em prática a aplicação da política de conscientização da mediação como ação estratégica de democratização e facilitação do exercício do direito fundamental de acesso à justiça da população" (Santos \& Ferreira, 2012).

O referido trabalho obteve resultados positivos. Além de conscientizar os alunos estagiários de que não há apenas a via jurisdicional para a resolução de conflitos, logrou êxito da prática mediativa em quatro (04) casos concretos, envolvendo processos que tramitavam nas Varas Cíveis e de Família da Comarca de Macaé, no primeiro semestre do ano de 2012 (Santos \& Ferreira, 2012).

O edital do Programa de Residência Jurídica lançado em 2013 teve a oferta de três (03) vagas para Macaé, a partir do convênio com a Prefeitura Municipal de Macaé. Segundo os registros fornecidos pela coordenadora à época, professora doutora Cibele Carneiro, no ano de 
2013, "o CAJUFF teve 224 clientes assistidos, 38 novas ações ingressadas e 58 audiências realizadas, fora os atendimentos apenas para orientação jurídica e, atualmente, são 160 processos em andamento" (Prefeitura Municipal de Macaé, 2014).

No ano de 2018, houve o lançamento de edital para Pós-Graduação lato sensu de Residência Jurídica em Resolução de Conflitos para Macaé, com a oferta de 10 vagas, sendo concedida bolsa para os cinco (05) primeiros classificados, com duração de 24 meses. A seleção para o curso de Residência Jurídica incluiu prova escrita, análise curricular e entrevista, inclusive avaliação de títulos.

Assim, desde o segundo semestre de 2018, foram retomados os atendimentos ao público, contando com uma equipe de residentes jurídicos. Os atendimentos ocorrem na presença do professor responsável, residentes jurídicos e alunos estagiários, no horário da disciplina, e são divididos por áreas do Direito.

O estágio supervisionado segue a seguinte ordem: cível, penal, trabalhista e família/sucessões. Assim, é oportunizado aos alunos o contato com as diferentes áreas do Direito a partir de demandas advindas de casos reais, observando o currículo da UFF.

\section{Tipos de Demandas Atendidas}

Nos atendimentos cíveis, constatou-se uma maior ocorrência de questões envolvendo relações de consumo, especialmente bancárias e cobranças indevidas, além de demandas referentes a direitos reais. Foram realizados atendimentos, consultas processuais, revisões contratuais, elaboradas notificações extrajudiciais e pareceres jurídicos, além da produção de petições iniciais para serem distribuídas no Juizado Especial Cível diretamente pelo assistido.

Em 2019, houve uma experiência de resolução de conflito por meio da mediação, em que as partes formalizaram acordo que permitiu a renovação de um contrato de locação e a assinatura de um instrumento de confissão de dívida.

Quanto a Direito do Trabalho, as demandam giram em torno de requerimento de verbas rescisórias, reconhecimento de vínculo empregatício e estabilidade provisória. Houve a distribuição de cerca de 20 reclamações trabalhistas nesse período, além da realização de atendimentos consultivos e de cálculos trabalhistas.

A equipe de Direito de Família e Sucessões registrou uma maior procura de casos relativos à fixação de alimentos e guarda com regulamentação, sendo distribuídas cerca de sete (07) ações e realizados atendimentos.

No que se refere ao Direito Penal, não estão sendo realizados atendimentos ao público externo, apenas atividades envolvendo casos simulados e discussões sobre temas pertinentes, porém foram prestadas consultorias acerca de auxílio reclusão e violência doméstica.

Cumpre informar ainda o recebimento de demandas do âmbito da Justiça Federal, principalmente previdenciárias, sendo prestadas orientações e realizados encaminhamentos aos assistidos, apesar de não haver uma equipe destinada especificamente a essa finalidade.

Considerando os registros dos atendimentos realizados ao longo dos anos, é possível observar uma grande procura da população pela assistência jurídica gratuita para todos os ramos do Direito. Tal demanda demonstra a necessidade do pleno funcionamento do núcleo de prática, de forma a ampliar o acesso à justiça.

\section{Contribuição do CAJUFF para a Sociedade e Perspectivas Futuras}

É possível observar o desenvolvimento do CAJUFF Macaé ao longo dos anos, a partir da oferta de Programas de Residência Jurídica, com substancial aumento do número de vagas e de bolsas, além da melhoria em sua estrutura física.

O CAJUFF funcionava inicialmente em um prédio situado no Centro de Macaé até agosto de 2013. Após essa data, passou a desenvolver suas atividades na Cidade Universitária, onde está localizada a UFF. Recentemente, houve uma melhora na estrutura física do núcleo de prática, sendo disponibilizada uma sala mais ampla, com a existência de local reservado 
para atendimento individualizado aos assistidos.

A demanda recebida pelo núcleo de prática é, em sua maioria, espontânea, conforme relato dos atores envolvidos nas atividades e seus relatórios de atendimento. No entanto, há assistidos que buscam atendimento a partir de encaminhamentos dos parceiros e de outros órgãos, notadamente da rede pública. Ocorre ainda procura por alunos e funcionários do próprio Polo Universitário pelos serviços de consultoria jurídica.

O CAJUFF Macaé, enquanto núcleo de prática jurídica, corresponde ao local onde os alunos concluintes do curso de Direito do ICM/UFF Macaé desenvolvem suas atividades de estágio, sendo, muitas vezes, a primeira oportunidade de contato prático-profissional em sua área de formação. Ademais, representa uma excelente oportunidade de experiência e aprimoramento profissional aos residentes jurídicos.

No que diz respeito aos serviços ofertados à comunidade, é realizado atendimento jurídico ao público, de forma gratuita, mediante prévio agendamento para a área do Direito correspondente à demanda apresentada. Os alunos estagiários, juntamente com os residentes jurídicos, sob a supervisão do professor, prestam a consulta jurídica a partir do relato do assistido e da análise da documentação apresentada.

Assim, são esclarecidos os aspectos jurídicos envolvidos no caso concreto, podendo ser elaborados pareceres jurídicos, instrumentos particulares, notificações extrajudiciais, cálculos trabalhistas e petições iniciais. A depender da demanda, bem como dos aspectos socioeconômicos do assistido, o residente jurídico poderá representá-lo judicialmente. Nesse caso, o advogado residente fará o acompanhamento processual e a orientação do assistido, bem como participará das audiências agendadas pelo Poder Judiciário, até a conclusão do processo, com seu efetivo trânsito em julgado.

Há casos ainda em que se observa a possibilidade de aplicação de meios alternativos para a resolução dos conflitos, por meio de práticas mediativas e de acordos extrajudiciais. A equipe do CAJUFF procederá nesse sentido quando identificar o benefício para o assistido e/ou maior agilidade na resolução da demanda, já que um processo judicial pode perdurar por muitos anos.

Insta salientar, a partir do relato dos professores e residentes atuantes no núcleo de prática, que muitos dos assistidos chegam aos atendimentos angustiados e fragilizados, com dúvidas e sentimento de insegurança por, muitas vezes, não saber como proceder para resolver sua demanda. Assim, reconhecem o CAJUFF Macaé como uma fonte segura de informações, com profissionais capacitados a prestar atendimento jurídico, ainda que em caráter exclusivamente consultivo, em alguns casos.

Nesse sentido, é possível observar que a principal forma de divulgação dos serviços do núcleo de prática ocorre por encaminhamento de outros órgãos, tais como Defensoria Pública, CEAM e Procuradoria Adjunta de Proteção e Defesa do Consumidor (PROCON), bem como por indicação de assistidos já atendidos e satisfeitos com o atendimento.

Em relação às perspectivas futuras, há ainda a previsão de que, em breve, a UFF receba um prédio próprio no pólo universitário para instalação da sede do ICM, que atualmente compartilha outros prédios da Cidade Universitária com as demais instituições ali situadas. Tal fato poderá contribuir ainda mais com as atividades do CAJUFF Macaé.

No entanto, apesar dos avanços, não se pode olvidar da necessidade de investimento contínuo, de modo a permitir um atendimento de qualidade à população e a continuidade das atividades do núcleo de prática jurídica do ICM/UFF Macaé.

\section{Considerações Finais}

Considerando todo o exposto, é possível observar que as instituições de ensino superior situadas no município de Macaé são bastante atuantes.

As universidades ofertam muito além do conhecimento acadêmico aos seus alunos, disponibilizam diversos serviços e atividades à população do município e seu entorno. Essas formas de atuação das universidades buscam retribuir à comunidade e difundir o 
conhecimento das salas de aula.

As atividades desenvolvidas nas instituições abrangem as diversas áreas do conhecimento, especialmente aquelas relacionadas aos cursos oferecidos por elas no município.

Dentre esses serviços, optou-se por fazer um recorte temático, abrangendo os núcleos de prática jurídica e, mais especificamente, o CAJUFF Macaé.

Assim, foi possível observar que os escritórios modelos contribuem positivamente para todos os atores envolvidos, são eles os alunos da graduação, os residentes jurídicos e a própria sociedade onde estão inseridos, a partir da disponibilização de uma assistência jurídica gratuita de qualidade.

O CAJUFF Macaé passou por diversas mudanças ao longo dos anos, com a oferta de editais de residência jurídica e alteração do local de funcionamento. Nesse sentido, conclui-se que atualmente possui uma estrutura mais consolidada, com a disponibilização de uma sala maior, climatizada e com espaços para atendimento individualizado, além de recursos básicos para o desenvolvimento de suas atividades.

Desse modo, observa-se a evolução do núcleo de prática do ICM/UFF Macaé, porém é necessária a aplicação de investimento contínuo, dispensando a devida atenção que o serviço demanda, de modo que as atividades não sejam interrompidas e seja possível ofertar um atendimento de qualidade à população.

A demanda existe e a grande procura para atendimentos nas mais diversas áreas reforça a tese de que os núcleos de prática demandam atenção e investimento. Assim, busca-se contribuir para a melhoria na qualidade do ensino para os alunos da graduação do curso de Direito e no acesso à justiça para a população do município e seu entorno.

Não há a pretensão no esgotamento do tema, mas apenas uma contribuição para o estudo e análise das atividades desenvolvidas pelas instituições de ensino superior situadas no município de Macaé, especialmente quanto ao núcleo de prática jurídica de uma Universidade Federal, situado em um campus do interior, como o CAJUFF Macaé.

Nesse sentido, promover o desenvolvimento de um turismo mais sustentável em Macaé é possível e aconselhável. Não obstante, para tanto, é indispensável que o planejamento e a gestão do turismo integrem os atores do poder público municipal, da iniciativa privada e do terceiro setor em torno de um horizonte comum e de longo prazo. Portanto, o turismo como fenômeno complexo e que se conecta de forma indissociável com as demais atividades do município, pode ser mais sustentável em Macaé, desde que tenha como princípios norteadores os benefícios sociais e econômicos para o maior número de pessoas, a conservação de seu patrimônio ambiental e a valorização de sua cultura, além de contar com uma estrutura política integrada e que sustente essa visão.

\section{Referências}

Altieri, M. A. (2012). Agroecologia: bases científicas para uma agricultura sustentável. (3a ed.) São Paulo, SP/ Rio de Janeiro, RJ: Expressão Popular e AS-PTA.

Bello, E., \& Ferreira, L. P. (2018). Clínicas de direitos humanos no Brasil: um estudo sobre seu processo de implementação e funcionamento na prática e no ensino jurídico. Revista de Estudos Constitucionais, Hermenêutica e Teoria do Direito, 10(2), 170-182. Unisinos.

CONSTITUIÇÃO DA REPÚBLICA FEDERATIVA DO BRASIL DE 1988. (1988. Recuperado em 10 dezembro, 2020, de http://www.planalto.gov.br/ccivil_03/constituicao/constituicao.htm.

Costa, A. B. (2008. As origens do núcleo de prática jurídica da UnB. Extensão em Foco, I, 15-24. Curitiba: UFPR.

Deslandes, M. S. S., \& Arantes, A. R. (2017. A extensão universitária como meio de transformação social e profissional. Sinapse Múltipla, 6 (2), 179-183.

Hudler, D. J., \& Furtado, M. S. (2015) A assistência jurídica em núcleos de prática jurídica e a possibilidade de extensão de prerrogativas da Defensoria Pública. Revista Jus Navigandi. 20, 4438, Recuperado em 16 
junho, 2020, de https://jus.com.br/artigos/41510.

PORTARIA $\mathrm{n}^{\circ}$ 1.886, de 30 de dezembro de 1994 (1994). Recuperado em 10 dezembro, 2020, de http://www.zumbidospalmares.edu.br/pdf/legislacao-ensino-juridico.pdf.

PREFEITURA MUNICIPAL DE MACAÉ. (2014). Funemac e UFF oferecem atendimento jurídico gratuito na Cidade Universitária. Recuperado em 10 dezembro, 2020, de http://www.macae.rj.gov.br/ensinosuperior/leitura/noticia/funemac-e-uff-oferecem-atendimento-juridicogratuito-na-cidade-universitaria.

RESOLUÇÃO CNE/CES n ${ }^{\circ}$ 9, de 29 de setembro de 2004 (2004). Recuperado em 10 dezembro, 2020, de http://portal.mec.gov.br/cne/arquivos/pdf/rces09_04.pdf.

Santos, C. C. C. M., \& Ferreira, M. V. R. (2012). Mediação: conscientização do tema no centro de assistência judiciária - CAJUFF Macaé. Anais do I Congresso Internacional Interdisciplinar em Sociais e Humanidades. Niterói, RJ, Brasil.

Santos, C. C. C. M., Pimentel, F. P., \& Marques, G. P. Y. (2015). Ensino jurídico e meios autocompositivos de solução de conflitos. CONINTER 4. 210-227. Foz do Iguaçu/PR: UNIOESTE.

Santos, C. C. C. M., \& Rezende, R. R. (2013). A mediação como instrumento transformador da cidadania. Mediação extrajudicial e justiça restaurativa (1a ed.). 45-60. Niterói: PPGSD.

Santos, C. C. C. M., Yagodnik, E. B., \& Marques, G. P. Y. (2014) O ensino jurídico e os meios consensuais de resolução de conflitos. Mediação: um panorama atual, I. Niterói: PPGSD

Sousa, J. G., Jr. (2006). Ensino do direito, núcleos de prática e de assessoria jurídica. Veredas do Direito, 3 (6), 123-144. Belo Horizonte.

UNIVERSIDADE FEDERAL DO RIO DE JANEIRO. (2020a). NUPEM/UFRJ recebe crianças para atividades científicas. jan. 2020a. Recuperado em 10 dezembro 2020, de http://www.macae.ufrj.br/nupem/index.php/novidades-slideshow/1167-nupem-ufrj-recebe-criancas-paraatividades-cientificas.

UNIVERSIDADE FEDERAL DO RIO DE JANEIRO. (2020b). Projeto de extensão do NUPEM/UFRJ promove capacitação para elaboração de adubo orgânico. Recuperado em 10 dezembro 2020, de http://www.macae.ufrj.br/nupem/index.php/novidades-slideshow/1168-projeto-de-extensao-do-nupem-ufrjpromove-capacitacao-para-elaboracao-de-adubo-organico.

UNIVERSIDADE FEDERAL FLUMINENSE. (2018). O CAJUFF Macaé é reconhecido como Núcleo de Prática Jurídica Professora Carla Fernandes de Oliveira. Recuperado em 10 dezembro 2020, de http://icm.sites.uff.br/?p=1367.

UNIVERSIDADE FEDERAL FLUMINENSE. (2019). Histórico do ICM: da chegada da UFF em Macaé aos dias atuais. Recuperado em 10 dezembro 2020, de http://icm.sites.uff.br/?page_id=190. 